\title{
Preparation and Characterization of Folate Targeting Magnetic Nanomedicine Loaded with Cisplatin
}

\author{
Minqiang Xie, Yiming Xu, Jie Liu, Tao Zhang, and Hongzheng Zhang \\ Department of Otorhinolaryngology, Head and Neck Surgery, Zhujiang Hospital, Southern Medical University, \\ Guangzhou 510282, China
}

Correspondence should be addressed to Minqiang Xie, min_qiang_x@hotmail.com

Received 24 January 2012; Revised 13 April 2012; Accepted 14 April 2012

Academic Editor: Sevan P. Davtyan

Copyright ( 2012 Minqiang Xie et al. This is an open access article distributed under the Creative Commons Attribution License, which permits unrestricted use, distribution, and reproduction in any medium, provided the original work is properly cited.

We used Aldehyde sodium alginate (ASA) as modifier to improve surfactivity and stability of magnetic nanoparticles, and folate acid (FA) as targeting molecule. $\mathrm{Fe}_{3} \mathrm{O}_{4}$ nanoparticles were prepared by chemical coprecipitation method. FA was activated and coupled with diaminopolyethylene glycol (NH2-PEG-NH2). ASA was combined with $\mathrm{Fe}_{3} \mathrm{O}_{4}$ nanoparticles, and FA-PEG was connected with ASA by Schiff's base formation. Then $\mathrm{Cl}^{-}$in cisplatin was replaced by hydroxyl group in ASA, and FAand ASA-modified cisplatin-loaded magnetic nanomedicine (CDDP-FA-ASA-MNPs) was prepared. This nanomedicine was characterized by transmission electron microscopy, dynamic lighterring scattering, phase analysis light scattering and vibrating sample magnetometer. The uptake of magnetic nanomedicine by nasopharyngeal and laryngeal carcinoma cells with folate receptor positive or negative expression were observed by Prussian blue iron stain and transmission electron microscopy. We found that CDDP-FA-ASA-MNPs have good water-solubility and stability. Mean diameter of $\mathrm{Fe}_{3} \mathrm{O}_{4}$ core was $8.17 \pm 0.24 \mathrm{~nm}$, hydrodynamic diameters was $110.90 \pm 1.70 \mathrm{~nm}$, and zeta potential was $-26.45 \pm 1.26 \mathrm{mV}$. Maximum saturation magnetization was $22.20 \mathrm{emu} / \mathrm{g}$. CDDP encapsulation efficiency was $49.05 \pm 1.58 \%$ ( $\mathrm{mg} / \mathrm{mg})$, and drug loading property was $14.31 \pm 0.49 \%$ (mg/mg). In vitro, CDDP-FA-ASA-MNPs were selectively taken up by HNE-1 cells and Hep-2 cells, which express folate receptor positively.

\section{Introduction}

Cancer is a serious threat to human life, and traditional surgery, radiotherapy, and chemotherapy are usually ineffective for advanced cancer. With the advances of molecular biology and materials science research, molecular targeted therapy becomes a hot spot in cancer research in recent years and also becomes an important part of cancer treatment [1]. Based on the advance of oncocytology and molecular biology, molecular targeted therapy utilizes some special antibodies or ligands to target at corresponding molecules in tumor tissues or cells. First, it can block or inhibit relevant molecules to inhibit tumor cell growth and metastasis or induce apoptosis, second it can deliver therapeutic drugs to tumor cells specifically, and, finally, it directly kills the targeted cancer cells without damaging normal cells [2]. The researches of folate targeted treatment of cancer have made great progress. Some anticancer drugs were attached to folate-induced carriers and were delivered to targeted cancer cells based on the special conjugation of folic acid and folate receptors [3-7]. Leamon et al. designed a tumor-targeted agent, named EC0225, with two distinct biological mechanisms of action [8]. This compound was constructed with a single folate molecule, extended by a hydrophilic peptidebased spacer, which was in turn attached to mitomycin and Vinca alkaloid units via two separate disulfide-containing linkers. EC0225 produced potent dose-responsive activity in vitro, and curative activity was observed against FR-positive xenograft tumors. Phase 1 clinical trials of EC0225 for the treatment of advanced malignancies have begun in March of 2007. Bae et al. developed a block copolymers nanocapsule with the function of folate targeting and $\mathrm{pH}$-sensitive releasing of loaded drugs [9]. The block copolymers are composed of hydrophilic PEG (polyethylene glycol poly)-folate and hydrophobic poly(aspartic acid)-doxorubicin(DOX). This nanocapsule can be selectively endocytosed by tumor cells by the way of folate-mediated targeting. Due to the acidic environment of cell endosome ( $\mathrm{pH}$ 5 6), DOX dissociates 
from the hydrophobic chain end of copolymers, thereby increasing the drug concentration in tumor tissue. Dhar et al. [10] prepared a folate targeted drug delivery system (SWNTPL-PEG-NH $\mathrm{N}_{2}$ ) in which cisplatin and folic acid conjugated with PEG were attached to single-walled carbon nanotubes. They found that nanodrugs could be selectively delivered to folate receptor positive tumor cells, released, and crosslinked with the nuclear DNA, and the level of intracellular platinum was much higher than traditional delivery. But it is hard to detect the targeting effect of their nanomedicines in vivo by imaging.

Our group has prepared a modified cisplatin-loaded magnetic nanomedicine and investigated its magnetic targeting effect on nasopharyngeal carcinoma cells CNE-2 and its xenograft tumors. We found its inhibiting tumor growth rates were $62.73 \%$ and $80.00 \%$ in vivo and in vitro, respectively $[11,12]$ and this nanomedicine could be located by electron microscopy and MRI in vivo [12]. In this paper, we prepared a new anticancer nanomedicine with both magnetic targeting and folate targeting function based on our previous studies [13], and investigated its physicochemical properties and targeting performance.

\section{Materials and Methods}

2.1. Materials. Agents and instruments: CNE-2 cells (from cell bank of Laboratory Animal center of Sun Yat-sen University, China), HNE-1 and Hep-2 cells (from cell bank of Central South University, China), sodium polymannuronate (Qingdao Crystal Rock Biology Development Co., Ltd., China), $\mathrm{FeCl}_{3} \cdot 6 \mathrm{H}_{2} \mathrm{O}$ (analytical grade) and $\mathrm{FeSO}_{4} \cdot 4 \mathrm{H}_{2} \mathrm{O}$ (analytical grade) (Guangzhou Chemical Reagent Factory, China), polyethylene glycol (relative molecular mass 2000, analytical grade) (Shanghai Jingchun Reagent Co., Ltd., China), Cisplatin (batch number: 703012CF, Qilu pharmaceutical Co., Ltd., China), FA (analytical grade), (Guangdong Guanghua Chemical Factory Co., Ltd., China), zeta potential and laser particle size analyzer (Brook Haven Instruments Co., USA), transmission electron microscopy (EOL-TEM 100, Japan), magnetic properties measurement system (Quantum Design, USA), DDS-11A conductivity meter (Shanghai Precision \& Scientific Instrument Co., Ltd., China).

\section{Methods}

3.1. Preparation of Aldehyde-Sodium-Alginate-(ASA-) Modified Magnetic $\mathrm{Fe}_{3} \mathrm{O}_{4}$ Nanoparticles. ASA was prepared using the methods reported by Laurienzo et al. (Figure 1(a)) [14]. Four grams of sodium alginate were dissolved in $100 \mathrm{~mL}$ double distilled water, and one gram of sodium periodate was added in dark condition and properly stirred. After reaction in dark condition for $24 \mathrm{~h}$ at $4^{\circ} \mathrm{C}, 5 \mathrm{~mL}$ of dehydrated alcohol was added to terminate reaction. The solution was ultrafiltrated until its volume was reduced to $40 \mathrm{~mL}$. The concentration of aldehyde group in the surface of oxidized sodium alginate was detected by potentiometric titration of hydroxylamine hydrochloride.
$\mathrm{FeCl}_{3} \cdot 6 \mathrm{H}_{2} \mathrm{O}(2.70 \mathrm{~g})$ and $\mathrm{FeSO}_{4} \cdot 4 \mathrm{H}_{2} \mathrm{O}(1.39 \mathrm{~g})$ were dissolved in $100 \mathrm{~mL}$ deionized water to produce a solution with concentrations of $0.01 \mathrm{~mol} / \mathrm{L}$ and $0.005 \mathrm{~mol} / \mathrm{L}$, respectively. $\mathrm{NH}_{3} \cdot \mathrm{H}_{2} \mathrm{O}$ (W/W: 25\%) was added at room temperature until $\mathrm{pH}$ was 9.50 and the solution turned dark. Magnetic wash was performed until the conductivity of the supernatant was $<50 \mu \mathrm{s}$. Magnetic nanoparticles (MNPs) were well dissociated in $60 \mathrm{~mL}$ deionized water by sonic oscillation.

Then, $40 \mathrm{~mL}$ prepared ASA was added into $60 \mathrm{~mL} \mathrm{Fe} \mathrm{O}_{4}$ MNPs solution, reacting for $40 \mathrm{~min}$ at $85^{\circ} \mathrm{C}$. After $4000 \mathrm{rpm}$ centrifugation, the supernatant was ultrafiltrated to remove free ASA until its conductivity was $<50 \mu$ s (Figure 1 (b)). The modified production was freeze-dried and reserved.

3.2. Preparation of FA- and ASA-Modified Magnetic $\mathrm{Fe}_{3} \mathrm{O}_{4}$ Nanoparticles. FA-PEG- $\mathrm{NH}_{2}$ was prepared by the methods reported by Ohguchi et al. [15]. FA $(0.58 \mathrm{~g})$ was dissolved in $30 \mathrm{~mL}$ dimethyl sulfoxide (DMSO), then $0.80 \mathrm{~g}$ dicyclohexyl carbodiimide (DCC) and $0.23 \mathrm{~g}$ N-hydroxysuccinimide (NHS) were added and stirred for $4 \mathrm{~h}$ to activate FA carboxyl group. And then, $2.40 \mathrm{~g}$ amino-terminated polyethylene gly$\operatorname{col}\left(\mathrm{NH}_{2}-\mathrm{PEG}_{2000}-\mathrm{NH}_{2}\right)$ was added and stirred for $8 \mathrm{~h}$ to link activated FA carboxyl group with PEG amino group. After that, $120 \mathrm{~mL}$ double distilled water was added, insoluble substance was removed by filtration, and the production was freeze-dried.

ASA-modified magnetic nanoparticles $(0.50 \mathrm{~g})$ were dissolved into $20 \mathrm{~mL} 0.40 \mathrm{M}$ natrium biboricum buffer solution $(\mathrm{pH}=9)$, and then $0.30 \mathrm{~g}$ FA-PEG-NH $\mathrm{N}_{2}$ was added. Sodium borohydride $(0.20 \mathrm{~g})$ was added while the solution was violently stirred for $8 \mathrm{~h}$ at room temperature (Figure $1(\mathrm{c})$ ). The production was dialyzed in distilled water for $3 \mathrm{~d}$ (molecular weight cutoff was 14000), and then freeze-dried.

3.3. Preparation of FA- and ASA-Modified CDDP-Loaded Magnetic Nanomedicines (CDDP-FA-ASA-MNPs). FA- and ASA-modified CDDP-loaded magnetic nanomedicine was prepared by using the rich unoxidized carboxyl groups($\mathrm{COO}-$ ) in ASA side chain to replace $\mathrm{Cl}^{-}$in cisplatin and form coordination complex, as described previously (Figure $1(\mathrm{~d})$ ) $[13,16]$. A certain amount of CDDP was added into suspension of FA- and ASA-modified magnetic nanoparticles and reacted in constant temperature shaker at $37^{\circ} \mathrm{C}$ for $24 \mathrm{~h}$. The production was kept in the dark after filtration by $0.22 \mu \mathrm{m}$ sterile filter. As the preparation method of carrier was modified, we found in optimization experiments that the best encapsulation efficiency and drug loading was available when CDDP/MNPs (counted by Fe) molar ratio was $2: 1$. So CDDP-FA-ASA-MNPs used in the following experiments were prepared by this ratio.

3.4. Physical and Chemical Characterization of CDDP-FAASA-MNPs. Hydrodynamic diameter and zeta potential: Detection was performed using zeta potential and laser particle size analyzer (Zeta PALS Brook Haven Instruments Co. USA). CDDP-FA-ASA-MNPs were diluted to a proper concentration (with $\mathrm{Fe} 0.20 \mathrm{mg} / \mathrm{mL}$ ), and $\mathrm{pH}$ value was adjusted to 7.40 by $0.1 \mathrm{~mol} / \mathrm{L} \mathrm{HCl}$ or $\mathrm{NaOH}$. The solution 
<smiles>CCOCC1(C)OC(C(=O)O[Na])C(C)(C)C(O)C1O</smiles>

Sodium alginate (SA)

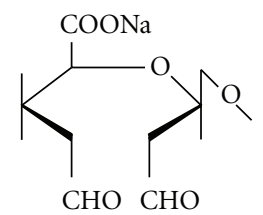

Aldehyde sodium alginate (ASA)

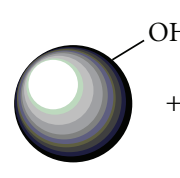

$\mathrm{Fe}_{3} \mathrm{O}_{4}$

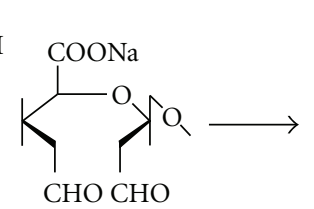

Aldehyde sodium alginate (ASA)

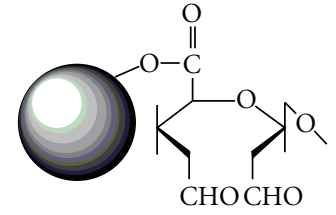

Aldehyde sodium alginate MNPs (ASAMNPs)

(a)

(b)

Folic acid (FA)<smiles>NC(CCC(=O)O)C(=O)O</smiles>

$+$<smiles>CC(C)(N)COC(C)(C)N</smiles>

$\operatorname{PEG}\left(\mathrm{NH}_{2}\right)_{2}$

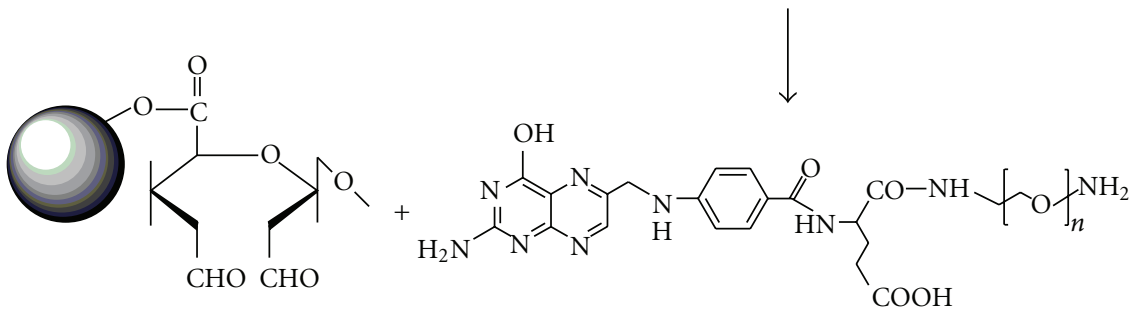

ASAMNPs

FA-PEG-NH 2

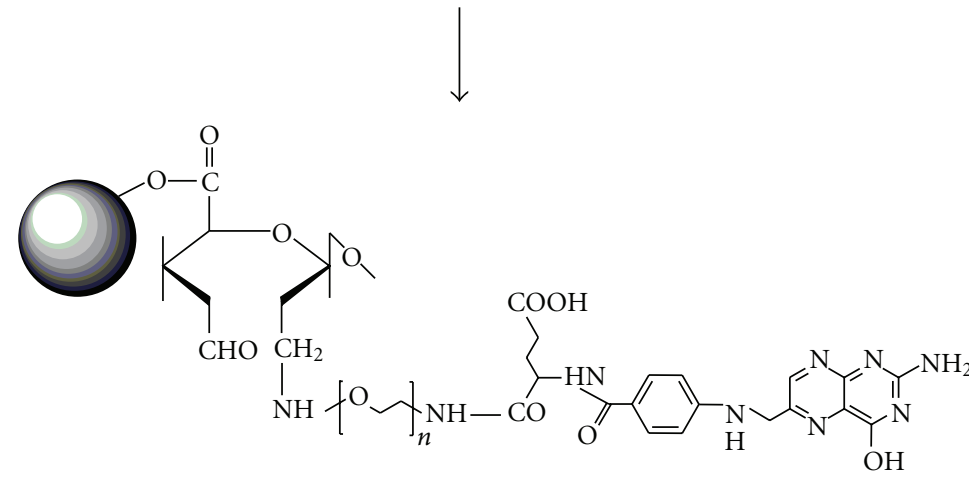

FA-ASAMNPs

(c)

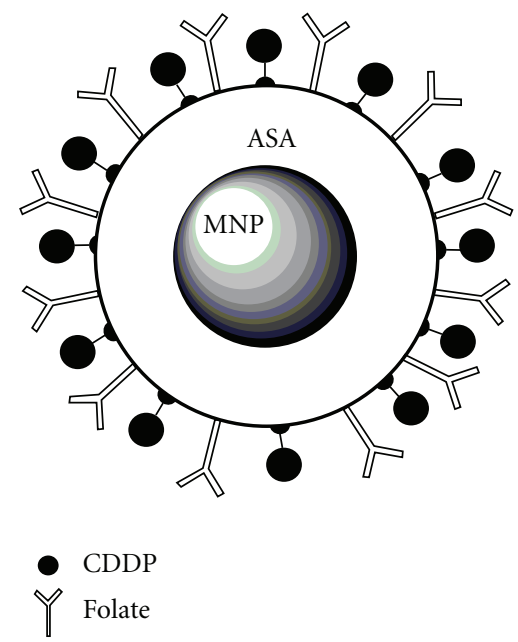

(d)

Figure 1: (a) SA oxidation. (b) Preparation of ASA-modified MNPs (ASA-MNPs). (c) Preparation of FA and ASA-modified magnetic Fe $\mathrm{O}_{4}$ nanoparticles. (d) Structure of CDDP-FA-ASA-MNPs.

was filtrated by $0.45 \mu \mathrm{m}$ filter before measurement. Measurement parameter: scattering angle was $90^{\circ}$, and temperature was $25^{\circ} \mathrm{C}$. The average values were calculated after several measurements.

Detection of core diameter, form, and dispersion: CDDPFA-ASA-MNPs were diluted to a proper concentration and dropped on polymer film-lined copper net. After being slowly dried, the sample was deposited with a layer of about $10-20 \mathrm{~nm}$ thick carbon film and then observed by transmission electron microscopy (JEOL-TEM 100).

Saturation magnetization: hysteresis curve of samples was determined between $-10 \mathrm{KOe} \sim 10 \mathrm{KOe}$ at $25^{\circ} \mathrm{C}$.

Drug loading: after ultrafiltration of CDDP-FA-ASAMNPs for $24 \mathrm{~h}$ at room temperature, CDDP content in ultrafiltrate was detected by O-phenylenediamine spectrophotometry method and the total mass of CDDP was calculated. The ultrafiltrate was freeze-dried and accurately weighted to calculate total mass of CDDP-FAASA-MNPs. Encapsulation efficiency and drug loading was calculated according to following equations: Encapsulation efficiency $(\%)=($ TMC/TCC $) * 100 \%$, Drug loading $(\%)=$ $(\mathrm{TMC} / \mathrm{TM}) * 100 \%$, where TMC was the total mass of CDDP in ultrafiltrate, TCC was the theoretical content of CDDP in ultrafiltrate, and TM was the total mass of CDDP-FA-ASA-MNPs [17].

3.5. CDDP-FA-ASA-MNPs Uptake into Nasopharyngeal and Laryngeal Carcinoma Cells. Prussian blue iron stain: exponentially growing nasopharyngeal carcinoma HNE-1 cells 
(folate receptor positive), CNE-2 cells (folate receptor negative) [18], and laryngeal carcinoma Hep-2 cells (folate receptor positive) were suspended in RPMI-1640 at a cell density of $2 * 10^{4} \cdot \mathrm{mL}^{-1}$ and then plated in a 24 -well culture plate separately $(500 \mathrm{uL} /$ well $)$. After adherent growth for $24 \mathrm{~h}$, cells were incubated for $6 \mathrm{~h}$ with CDDP-FA-ASA-MNPs and FA-ASA-MNPs, which were diluted with RPMI-1640. The drug concentrations calculated according to Fe content were 5,10 , and $20 \mu \mathrm{g} \cdot \mathrm{mL}^{-1}$ separately. After incubation, culture solution was removed and cells were washed three times with cold PBS ( $\mathrm{pH}$ 7.40) to remove unbound MNPs, fixed with $4 \%$ paraformaldehyde for $10 \mathrm{~min}$ at room temperature. After being washed with double distilled water, cells were stained with Prussian blue for $30 \mathrm{~min}$ at room temperature. Nucleuses were stained with neutral red as a control. The slides were observed and photographed under inverted microscope.

Transmission electron microscopy: HNE-1 cells, CNE-2 cells, and Hep-2 cells were incubated with CDDP-FA-ASAMNPs separately as described above. After centrifugation, cells were fixed and dehydrated and then were embedded in epoxy resin and cut into extrathin sections. The sections were stained with uranyl acetate and lead citrate and observed by transmission electron microscopy to detect cells uptake of MNPs. The observations included cell morphology, cell membrane, nucleus, organelles, pinosomes in cytoplasm, and electron dense MNPs in pinosomes.

\section{Results and Discussion}

4.1. Preparation of CDDP-FA-ASA-MNPs and Content of $C D D P$. After being oxidated by sodium periodate, C2-C3 linkage in SA was broken, which leads to the formation of two aldehyde groups (-CHO), as seen in Figure 1(a). As hydroxylamine hydrochloride can react with aldehyde groups of ASA, which leads to formation of HCL, we calculated the degree of SA oxidation according to the amount of $\mathrm{NaOH}$ used in titration. The degree of oxidation was $21.78 \pm 0.98 \%$, in agreement with the literature data $[19,20]$, which means that there was an aldehyde group in every five SA monomers.

Hydrosoluble $\mathrm{Fe}_{3} \mathrm{O}_{4}$ magnetic nanoparticles were prepared by chemical coprecipitation method and modified by ASA (Figure 1(b)). Using amino-terminated polyethylene glycol as a bridge medium, we successfully connected folic acid with ASA, and prepared FA- and ASA-modified MNPs (FA-ASA-MNPs). There were lots of carboxyl groups in SA side chain. As hydroxyl groups were formed in the surface of $\mathrm{Fe}_{3} \mathrm{O}_{4}$ MNPs after addition of ammonia water, $\mathrm{Fe}_{3} \mathrm{O}_{4}$ MNPs were conjugated with ASA by the interaction of hydroxyl and carboxyl groups, which led to formation of stable iron carboxylate. After being activate by DCC and NHS, carboxyl group in FA was conjugated with one amino group in amino-terminated PEG $\left(\mathrm{NH}_{2}\right.$-PEG- $\left.\mathrm{NH}_{2}\right)$, which led to the formation of FA-PEG-NH $\mathrm{N}_{2}$. And then the other amino group in FA-PEG- $\mathrm{NH}_{2}$ was connected with aldehyde group in ASA in the surface of MNPs by Schiff's base formation. The rich unoxidized carboxyl groups (COO-) in ASA side chain were replaced by $\mathrm{Cl}^{-}$in cisplatin with formation of coordination complex, and FA- and ASAmodified CDDP-loaded magnetic nanomedicines (CDDPFA-ASA-MNPS) were finally prepared (Figures $1(\mathrm{c})$ and $1(\mathrm{~d}))$. Due to the introduction of PEG, these MNPs have improved hydrosolubility and stability.

CDDP content was detected by O-phenylenediamine spectrophotometry method. Standard curve was shown in Figure 2, and the regression equation was $Y=0.1129 X-$ $0.1871, R^{2}=0.9861$. The drug loading of cisplatin was $14.31 \pm$ $0.49 \%$, and encapsulation efficiency was $49.05 \pm 1.58 \%$ as calculated.

4.2. Hydrodynamic Diameter and Zeta Potential. Dynamic light scattering particle sizes of CDDP-FA-ASA-MNPs were detected by laser particle size analyzer. And the result showed a $\log$ normal distribution. Mean hydrodynamic diameter of CDDP-FA-ASA-MNPs was $110.90 \pm 1.70 \mathrm{~nm}$ (Figure 3), smaller than FA-ASA-MNPs $(141.90 \pm 1.30 \mathrm{~nm}$, Figure 4). The reason might be that extended linear molecule of CDDP was coiled after being conjugated with ASA. The isoelectric point of nude $\mathrm{Fe}_{3} \mathrm{O}_{4}$ MNPs solution was 6.5. When the $\mathrm{pH}$ value of solution is less than the isoelectric point, MNPs positively charged, otherwise negatively charged [21]. Zeta potential of CDDP-FA-ASA-MNPs in neutral aqueous media was $-26.45 \pm 1.26 \mathrm{mV}$ (Figure 5). The nanoparticles were excluded mutually due to their negative potential, which means that they present good stability. However, this potential was lower than that of FA-ASA-MNPs $(-42.39 \pm$ $3.11 \mathrm{mV}$, Figure 6). It might be due to the decrease of negative charge after CDDP was conjugated with carboxyl group. Zeta potential is an important indicator of polymer stability, and polymers with greater potential have better stability. The result showed that our folate targeting MNPs had good stability before and after being loaded with CDDP and could hold its dispersion for a long time. The targeting ability of MNPs and the ability to avoid uptake by reticuloendothelial system (RES), which are critical factors for anticancer effect in vivo, depend on their surface property and particle diameter. SA is negatively charged hydrophilic compound with lots of carboxyl groups, which we got consistent with the zeta potential. Compared to other surface modifiers, SA would reduce the uptake by Kupffer cells in liver, therefore circulation time in vivo of ASA modified MNPs would be prolonged. Furthermore, after MNPs were modified by ASA and FA-PEG- $\mathrm{NH}_{2}, \mathrm{Fe}_{3} \mathrm{O}_{4}$ was packed with hydrophilic compounds. It was not so easy for MNPs to combine with serum opsonin in blood, and this would also reduce the opsonin-mediated phagocytosis by macrophages. MNPs can go through endothelial cell gap into cancer tissue due to the enhanced permeability and retention (EPR) effect, and MNPs uptake by cancer is depended on particle size. As our MNPs were modified by folate, with mean hydrodynamic diameter $<120 \mathrm{~nm}$, they could go through vascular endothelial cells and easily selectively be uptaken by FR-positive tumor cells in theory.

4.3. Core Diameter and Magnetic Responsibility. As shown in Figure 7, CDDP-FA-ASA-MNPs were basically dispersed 


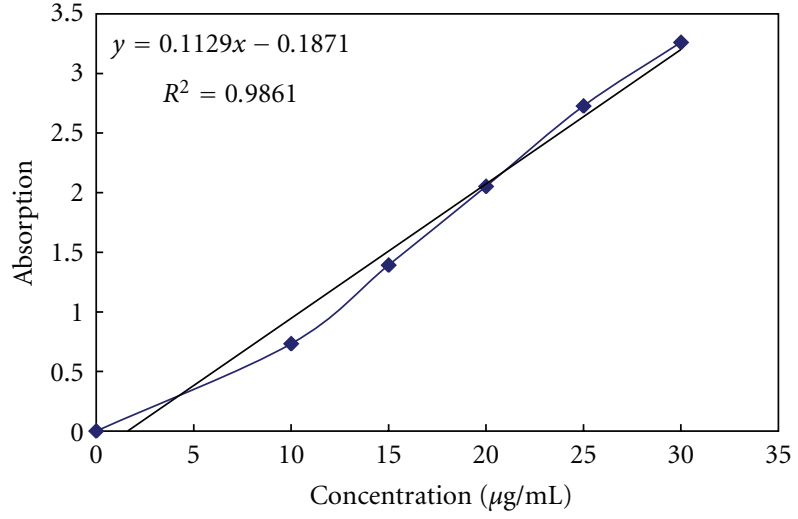

Figure 2: Standard curve of CDDP content.

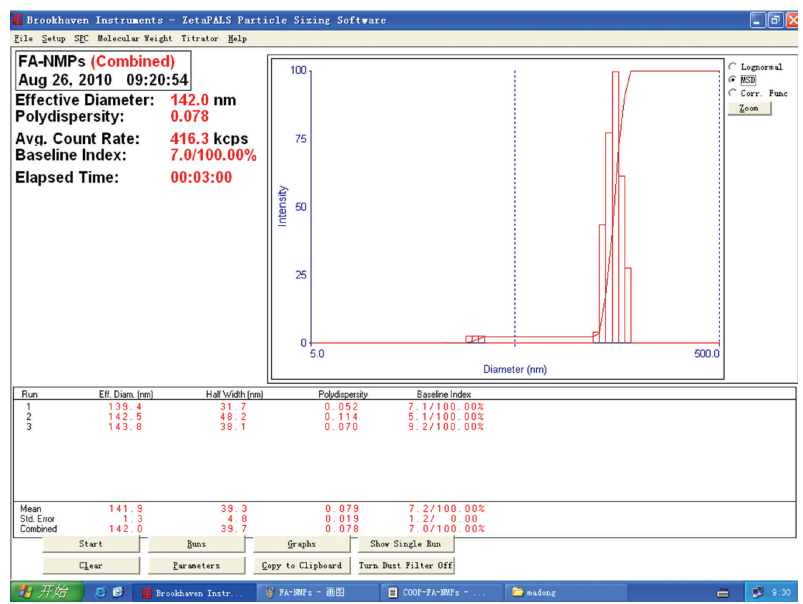

FIgure 3: Particle size distribution of FA-ASA-MNPs detected by dynamic laser scattering.

into single particles under TEM, with round surface shape. Because of its small particle size and a variety of active groups in its surface after modifications, a slight aggregation was seen Figure 7(a). One hundred MNPs were selected randomly and their diameters were detected. The mean core diameter was $8.12 \pm 0.24 \mathrm{~nm}$, with normal distribution showed in histogram Figure 7(b). Maximum saturation magnetization was $22.20 \mathrm{emu} / \mathrm{g}$ and coercivity was zero Figure 7(c). It meant that our MNPs had good magnetic responsibility and superparamagnetism.

4.4. Cell Targeting of CDDP-FA-ASA-MNPs. In order to examine the cell targeting of CDDP-FA-ASA-MNPs, we incubated HNE-1 and Hep-2 cells (FR positive) and CNE2 cells (FR negative) with CDDP-FA-ASA-MNPs in deferent concentrations for $6 \mathrm{~h}$ and then carried out Prussian blue iron stain. Prussian blue iron stain is an effective method to investigate biodistribution of iron oxide nanoparticles, as showed in many experimental results [22]. As $\mathrm{Fe}_{3} \mathrm{O}_{4}$ can interact with Prussian blue staining solution and form blue $\mathrm{Fe}_{4}\left(\mathrm{Fe}(\mathrm{CN})_{6}\right)_{3}$ particles in situ, distribution of iron oxide nanoparticles after uptake by cells can be seen directly [23].

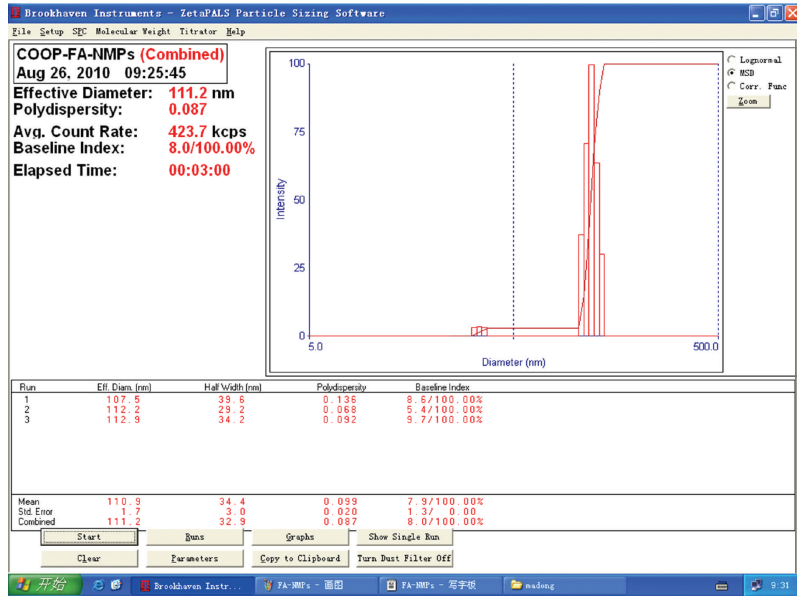

FIgURE 4: Particle size distribution of CDDP-FA-ASA-MNPs detected by dynamic laser scattering.

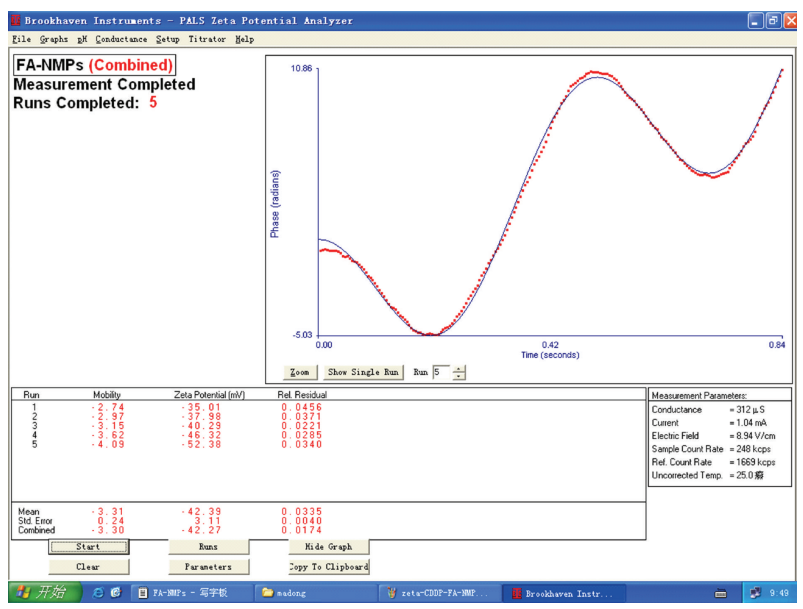

Figure 5: Zeta potential trend graph of FA-ASA-MNPs.

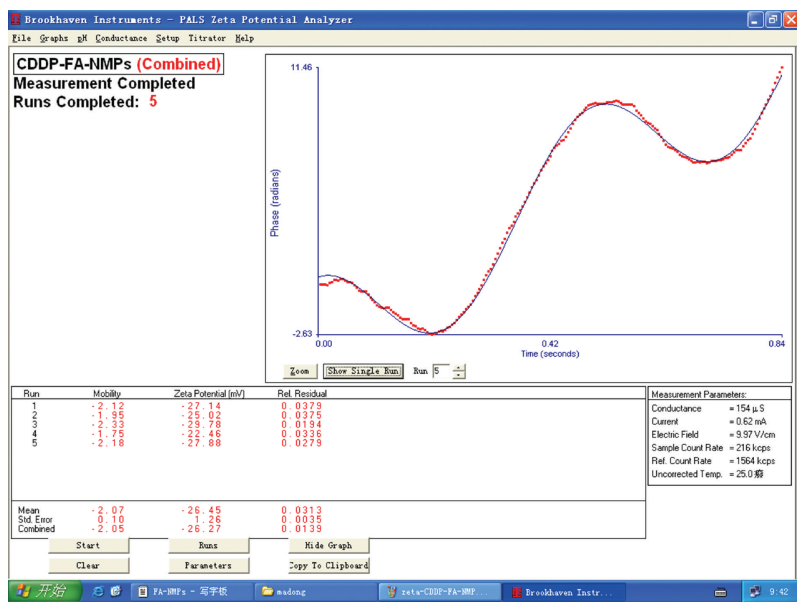

FIGURE 6: Zeta potential trend graph of CDDP-FA-ASA-MNPs. 


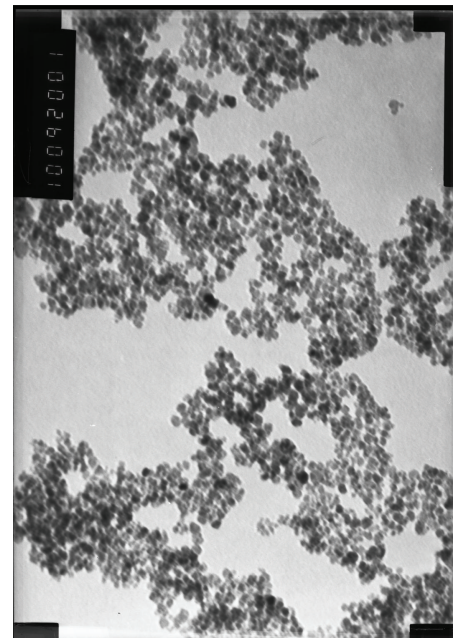

(a)

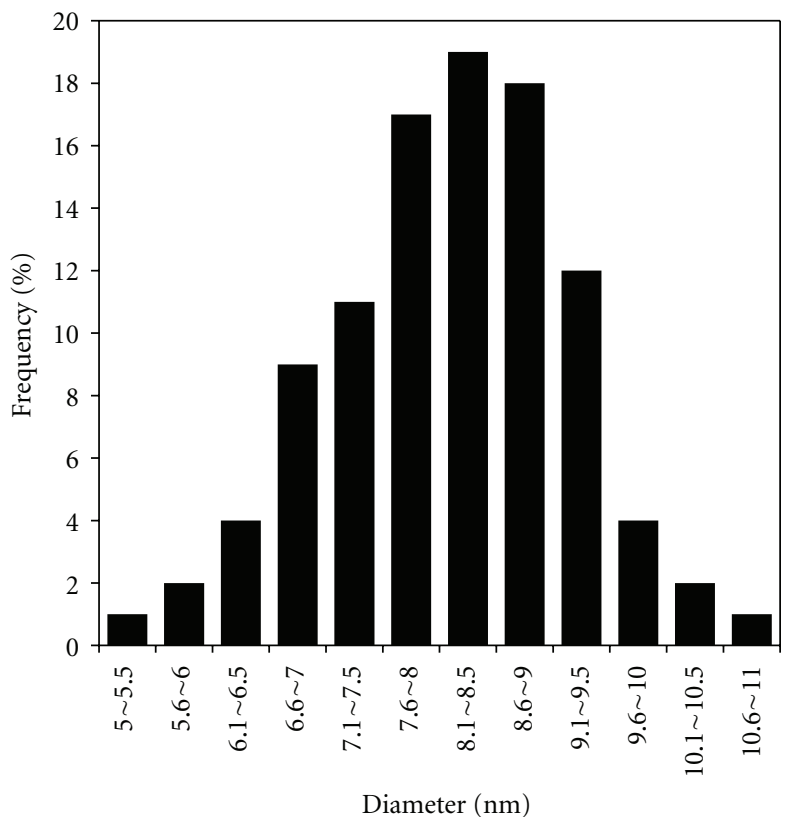

(b)

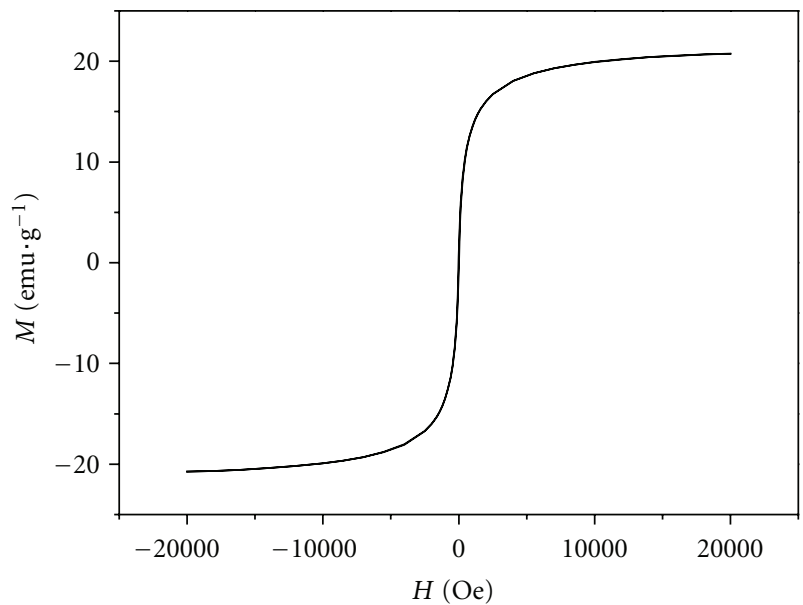

(c)

FIgURE 7: (a) Transmission electron microscope graph of FA-CDDP-ASA-MNP, 100000x. (b) Particle size distribution. (c) Saturation magnetization curve.

The results showed that lots of $\mathrm{Fe}_{3} \mathrm{O}_{4}$ nanoparticles were seen in cytoplasm of HNE-1 and Hep-2 cells after CDDPFA-ASA-MNPs with Fe content of $5 \mu \mathrm{g} \cdot \mathrm{mL}^{-1}$ were given, and there were no blue particles in cytoplasm of CNE-2 cells that were FR negative (Figures 8(a), 8(c), and 8(e)). In practice, we found the best result would be achieved in Fe content of $5 \mu \mathrm{g} \cdot \mathrm{mL}^{-1}$ and incubation of $6 \mathrm{~h}$. Prolonging the incubation period would lead to gathering of small amount of MNPs around the membrane of FR-negative CNE-2 cells, and inadequate incubation would reduce the uptake of MNPs. In out experiments, cells apoptosis and death were observed in cultures with $\mathrm{Fe}$ content of $10 \mu \mathrm{g} \cdot \mathrm{mL}^{-1}$ (equivalent to cisplatin concentration $2.80 \mu \mathrm{g} \cdot \mathrm{mL}^{-1}$ ), and over staining and background pollution were found in those of $20 \mu \mathrm{g} \cdot \mathrm{mL}^{-1}$. The results showed that CDDP-FA-ASA-MNPs uptake by FR-positive cells was achieved through FR pathway, which is in agreement with the results in other cellular and molecular targeting model performed by other scholars [24-26]. The results of TEM showed that there were lots of high electron dense MNPs in pinosomes in cytoplasm of HNE-1 and Hep2 cells, and none in CNE- 2 cells, which is consistent with the results of Prussian blue stain (Figures $8(\mathrm{~b}), 8(\mathrm{~d})$, and $8(\mathrm{f})$ ). It further confirmed selective uptake of our FA targeting MNPs by FR-positive HNE-1 and Hep-2 cells.

Most cancer chemotherapeutics are administered either orally or intravenously to achieve systemic distribution for 


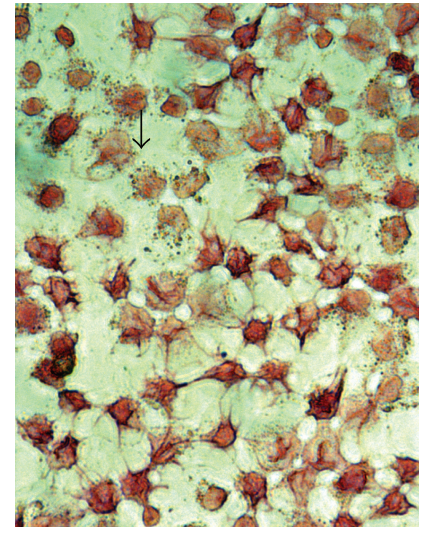

(a)

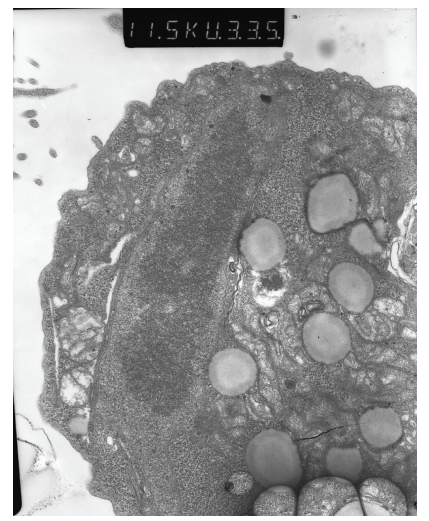

(d)

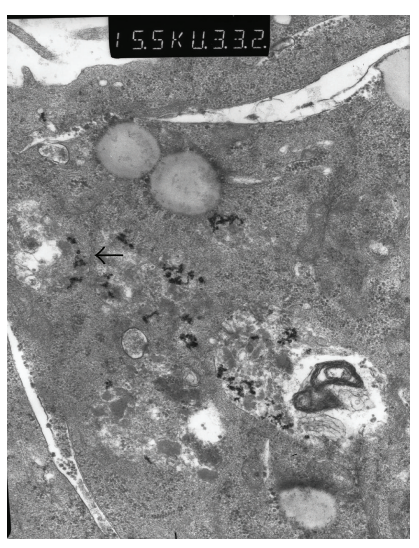

(b)

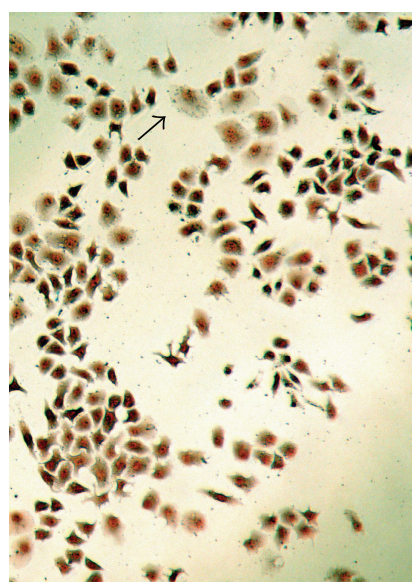

(e)

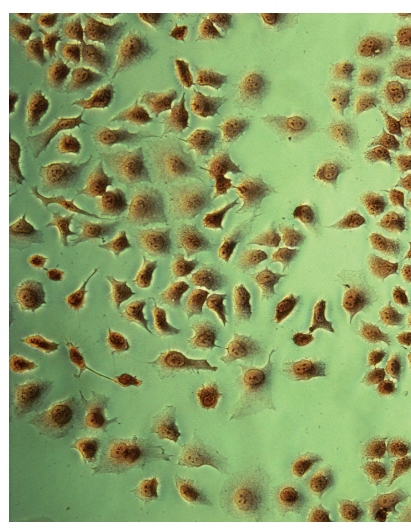

(c)

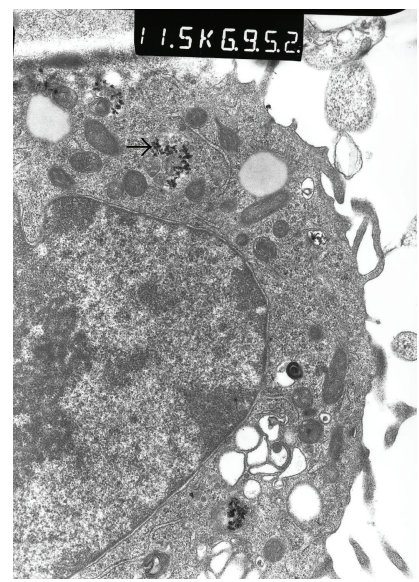

(f)

Figure 8: Cells were incubated with CDDP-FA-ASA-MNPs (Fe content was $5 \mu \mathrm{g} \cdot \mathrm{mL}^{-1}$ ) for $6 \mathrm{~h}$. (a), (c), (e) Iron stain, 200x. (a) HNE-1 cells (FR positive), blue stain particles were observed in cytoplasm. (b) Electron microscope image for HNE-1 cells, pinosomes contained magnetic nanoparticles were observed in cytoplasm, 155000x. (c) CNE-2 cells (FR negative), blue stain particles were not observed in cytoplasm. (d) Electron microscope image for CNE-2 cells, magnetic nanoparticles were not observed in cytoplasm, 115000x. (e) Hep-2 cells (FR positive), blue-stain particles were observed in cytoplasm. (f) Electron microscope image for Hep-2 cells, pinosomes contained magnetic nanoparticles were observed in cytoplasm, as arrow shown, 115000x.

effective treatment. Due to lack of selectivity, conventional chemotherapy causes significant damage to rapidly proliferating normal cells. The major goal of targeted therapies is to target the chemotherapeutics to cancer cell, which ultimately reduces the side effects. FR is believed to be a useful biological target for cancer due to its overexpression on malignant cancer cells, and recent reports of folate targeted drug therapies have demonstrated impressive potency against tumor xenografts, without most of the undesirable toxicities [27]. But FR is also expressed in some normal tissues (such as kidneys epithelial cells) and chronic inflammation tissues [28]. In this study, we prepared a folate targeted magnetic nanomedicine. Besides of active folate targeted function, it has more advantages. (a) Passive targeting: due to the enhanced permeability and retention (EPR) effect, nanomedicines will accumulate in sites of cancer tissue [29]. (b) Magnetic targeting: under the influence of an external magnetic field, magnetic nanoparticles will be held in the targeted area and concentrated at the specific site after being injected in the vascular system [30]. (c) Imaging: superparamagnetic nanoparticles can be used as MR contrast agents and used in clinical diagnosis due to their effects in signal reduction on T2-weighted images ("negative" contrast) [31]. (d) Intracellular hyperthermia: followed by application of an external alternating magnetic field, targeting magnetic nanoparticles to tumor tissue will induce heat through Néel relaxation loss of the magnetic nanoparticles. The temperature in tumor tissue is increased to above $43^{\circ} \mathrm{C}$, which causes necrosis of cancer cells but does not damage surrounding normal tissue [32].

There were some previous studies that prepared targeting drugs by connecting folic acid with paclitaxel, taxol and carboplatin, hoping to improve drug delivery efficiency [3335]. As the active agent of such drugs could not dissociate effectively after uptake by cells, it failed to obtain desired effect in experiments. In this paper, the connection of CDDP with ASA was reversible $[13,16]$, and it was presumed theoretically that CDDP could be effectively dissociated 
within cells, but actual effect in vivo needs to be confirmed by further investigations.

\section{Conclusions}

Hydrosoluble FA targeting CDDP-loaded MNPs (CDDP-FAASA-MNPs) were prepared by modification by ASA and FA-PEG. These nanoparticles had stable property and good folate-targeting ability, and they were prone to selectively taken up by FR-positive nasopharyngeal carcinoma HNE-1 cells and laryngeal carcinoma Hep-2 cells, as demonstrated by a number of characterization and uptake experiments in vitro.

\section{Acknowledgments}

This work was financially supported by National Natural Science Foundation of China (30672297, 21103052), Guangdong Natural Science Foundation (10251051501000001), Science and Technology Planning Project of Guangdong Province, China (2009B080701038), and Specialized Research Fund for the Doctoral Program of Higher Education of China (20114433110001).

\section{References}

[1] C. Sawyers, “Targeted cancer therapy," Nature, vol. 432, no. 7015, pp. 294-297, 2004.

[2] K. Cho, X. Wang, S. Nie, Z. G. Chen, and D. M. Shin, “Therapeutic nanoparticles for drug delivery in cancer," Clinical Cancer Research, vol. 14, no. 5, pp. 1310-1316, 2008.

[3] T. A. Yap, C. P. Carden, and S. B. Kaye, "Beyond chemotherapy: targeted therapies in ovarian cancer," Nature Reviews Cancer, vol. 9, no. 3, pp. 167-181, 2009.

[4] M. Prabaharan, J. J. Grailer, S. Pilla, D. A. Steeber, and S. Gong, "Folate-conjugated amphiphilic hyperbranched block copolymers based on Boltorn H40, poly(l-lactide) and poly(ethylene glycol) for tumor-targeted drug delivery," Biomaterials, vol. 30, no. 16, pp. 3009-3019, 2009.

[5] W. Xia, A. R. Hilgenbrink, E. L. Matteson, M. B. Lockwood, J. X. Cheng, and P. S. Low, "A functional folate receptor is induced during macrophage activation and can be used to target drugs to activated macrophages," Blood, vol. 113, no. 2, pp. 438-446, 2009.

[6] S. Chen, X. Z. Zhang, S. X. Cheng, R. X. Zhuo, and Z. W. Gu, "Functionalized amphiphilic hyperbranched polymers for targeted drug delivery," Biomacromolecules, vol. 9, no. 10, pp. 2578-2585, 2008.

[7] R. G. Pillai, M. Forster, M. Perumal et al., "Imaging pharmacodynamics of the $\alpha$-folate receptor-targeted thymidylate synthase inhibitor BGC 945," Cancer Research, vol. 68, no. 10, pp. 3827-3834, 2008.

[8] C. P. Leamon, J. A. Reddy, I. R. Vlahov et al., "Preclinical antitumor activity of a novel folate-targeted dual drug conjugate," Molecular Pharmaceutics, vol. 4, no. 5, pp. 659-667, 2007.

[9] K. H. Bae, Y. Lee, and T. G. Park, "Oil-encapsulating PEOPPO-PEO/PEG shell cross-linked nanocapsules for targetspecific delivery of paclitaxel," Biomacromolecules, vol. 8, no. 2, pp. 650-656, 2007.
[10] S. Dhar, Z. Liu, J. Thomale, H. Dai, and S. J. Lippard, “Targeted single-wall carbon nanotube-mediated $\mathrm{Pt}(\mathrm{IV})$ prodrug delivery using folate as a homing device," Journal of the American Chemical Society, vol. 130, no. 34, pp. 11467-11476, 2008.

[11] Z. Li, M. Q. Xie, S. Chen, and L. Wang, "Complexing cisdiaminedichloroplatinum-loaded magnetic nano-medicine for treating nasopharyngeal carcinoma in vitro," Journal of Clinical Rehabilitative Tissue Engineering Research, vol. 13, no. 29, pp. 5637-5640, 2009.

[12] H. Z. Zhang, M. Q. Xie, Z. Kang, H. Shen, and L. Wang, "Targeted distribution of cis-platin magnetic nanoparticles in mice," Journal of Southern Medical University, vol. 28, no. 10, pp. 1756-1759, 2008.

[13] M. Q. Xie, S. J. Chen, X. Q. Xu, Z. Li, H. Shen, and J. Xu, "Preparation of two kinds of superparamagnetic carrierssupported cis-platinum complexes and the comparison of their characteristics," Chinese Science Bulletin, vol. 51, no. 2, pp. 151-157, 2006.

[14] P. Laurienzo, M. Malinconico, A. Motta, and A. Vicinanza, "Synthesis and characterization of a novel alginate-poly (ethylene glycol) graft copolymer," Carbohydrate Polymers, vol. 62, no. 3, pp. 274-282, 2005.

[15] Y. Ohguchi, K. Kawano, Y. Hattori, and Y. Maitani, "Selective delivery of folate-PEG-linked, nanoemulsion-loaded aclacinomycin A to KB nasopharyngeal cells and xenograft: effect of chain length and amount of folate-PEG linker," Journal of Drug Targeting, vol. 16, no. 9, pp. 660-667, 2008.

[16] X. Q. Xu, H. Shen, J. R. Xu, M. Q. Xie, and X. J. Li, "The colloidal stability and core-shell structure of magnetite nanoparticles coated with alginate," Applied Surface Science, vol. 253, no. 4, pp. 2158-2164, 2006.

[17] X. Han, J. Liu, M. Liu et al., "9-NC-loaded folate-conjugated polymer micelles as tumor targeted drug delivery system: preparation and evaluation in vitro," International Journal of Pharmaceutics, vol. 372, no. 1-2, pp. 125-131, 2009.

[18] H. Zhang, M. Q. Xie, Z. Li, and G. Lin, "Expression of folate receptor in the tissues and cells of nasopharyngeal carcinoma," China Journal of Modern Medicine, vol. 19, no. 6, pp. 833-836, 2009.

[19] T. Boontheekul, H. J. Kong, and D. J. Mooney, "Controlling alginate gel degradation utilizing partial oxidation and bimodal molecular weight distribution," Biomaterials, vol. 26, no. 15, pp. 2455-2465, 2005.

[20] P. Laurienzo, M. Malinconico, A. Motta, and A. Vicinanza, "Synthesis and characterization of a novel alginate-poly (ethylene glycol) graft copolymer," Carbohydrate Polymers, vol. 62, no. 3, pp. 274-282, 2005.

[21] W. Zhang, H. Shen, M. Q. Xie et al., "Core-shell structure and magnetic properties of magnetic nanoparticles modified by citric acid," Acta Scientiarum Natralium Universitatis Sunyatseni, vol. 47, no. 2, pp. 58-61, 2008.

[22] R. A. Kroll, M. A. Pagel, L. L. Muldoon, S. Roman-Goldstein, and E. A. Neuwelt, "Increasing volume of distribution to the brain with interstitial infusion: dose, rather than convection, might be the most important factor," Neurosurgery, vol. 38, no. 4, pp. 746-754, 1996.

[23] G. Hong, R. Yuan, B. Liang, J. Shen, X. Yang, and X. Shuai, "Folate-functionalized polymeric micelle as hepatic carcinoma-targeted, MRI-ultrasensitive delivery system of antitumor drugs," Biomedical Microdevices, vol. 10, no. 5, pp. 693700, 2008.

[24] C. Yang, A. Rait, K. F. Pirollo, J. A. Dagata, N. Farkas, and E. H. Chang, "Nanoimmunoliposome delivery of superparamagnetic iron oxide markedly enhances targeting and uptake in 
human cancer cells in vitro and in vivo," Nanomedicine, vol. 4, no. 4, pp. 318-329, 2008.

[25] C. Sun, R. Sze, and M. Zhang, "Folic acid-PEG conjugated superparamagnetic nanoparticles for targeted cellular uptake and detection by MRI," Journal of Biomedical Materials Research A, vol. 78, no. 3, pp. 550-557, 2006.

[26] H. Choi, S. R. Choi, R. Zhou, H. F. Kung, and I. W. Chen, "Iron oxide nanoparticles as magnetic resonance contrast agent for tumor imaging via folate receptor-targeted delivery," Academic Radiology, vol. 11, no. 9, pp. 996-1004, 2004.

[27] P. S. Low and S. A. Kularatne, "Folate-targeted therapeutic and imaging agents for cancer," Current Opinion in Chemical Biology, vol. 13, no. 3, pp. 256-262, 2009.

[28] M. D. Salazar and M. Ratnam, "The folate receptor: what does it promise in tissue-targeted therapeutics?" Cancer and Metastasis Reviews, vol. 26, no. 1, pp. 141-152, 2007.

[29] E. Gullotti and Y. Yeo, "Extracellularly activated nanocarriers: a new paradigm of tumor targeted drug delivery," Molecular Pharmaceutics, vol. 6, no. 4, pp. 1041-1051, 2009.

[30] M. Chidambaram, R. Manavalan, and K. Kathiresan, "Nanotherapeutics to overcome conventional cancer chemotherapy limitations," Journal of Pharmacy and Pharmaceutical Sciences, vol. 14, no. 1, pp. 67-77, 2011.

[31] A. Ito, M. Shinkai, H. Honda, and T. Kobayashi, "Medical application of functionalized magnetic nanoparticles," Journal of Bioscience and Bioengineering, vol. 100, no. 1, pp. 1-11, 2005.

[32] T. Kobayashi, "Cancer hyperthermia using magnetic nanoparticles," Biotechnology Journal, vol. 6, no. 11, pp. 1342-1347, 2011.

[33] J. A. Reddy, V. M. Allagadda, and C. P. Leamon, “Targeting therapeutic and imaging agents to folate receptor positive tumors," Current Pharmaceutical Biotechnology, vol. 6, no. 2, pp. 131-150, 2005.

[34] J. W. Lee, J. Y. Lu, P. S. Low, and P. L. Fuchs, "Synthesis and evaluation of taxol-folic acid conjugates as targeted antineoplastics," Bioorganic and Medicinal Chemistry, vol. 10, no. 7, pp. 2397-2414, 2002.

[35] O. Aronov, A. T. Horowitz, A. Gabizon, and D. Gibson, "Folate-targeted PEG as a potential carrier for carboplatin analogs. Synthesis and in vitro studies," Bioconjugate Chemistry, vol. 14, no. 3, pp. 563-574, 2003. 

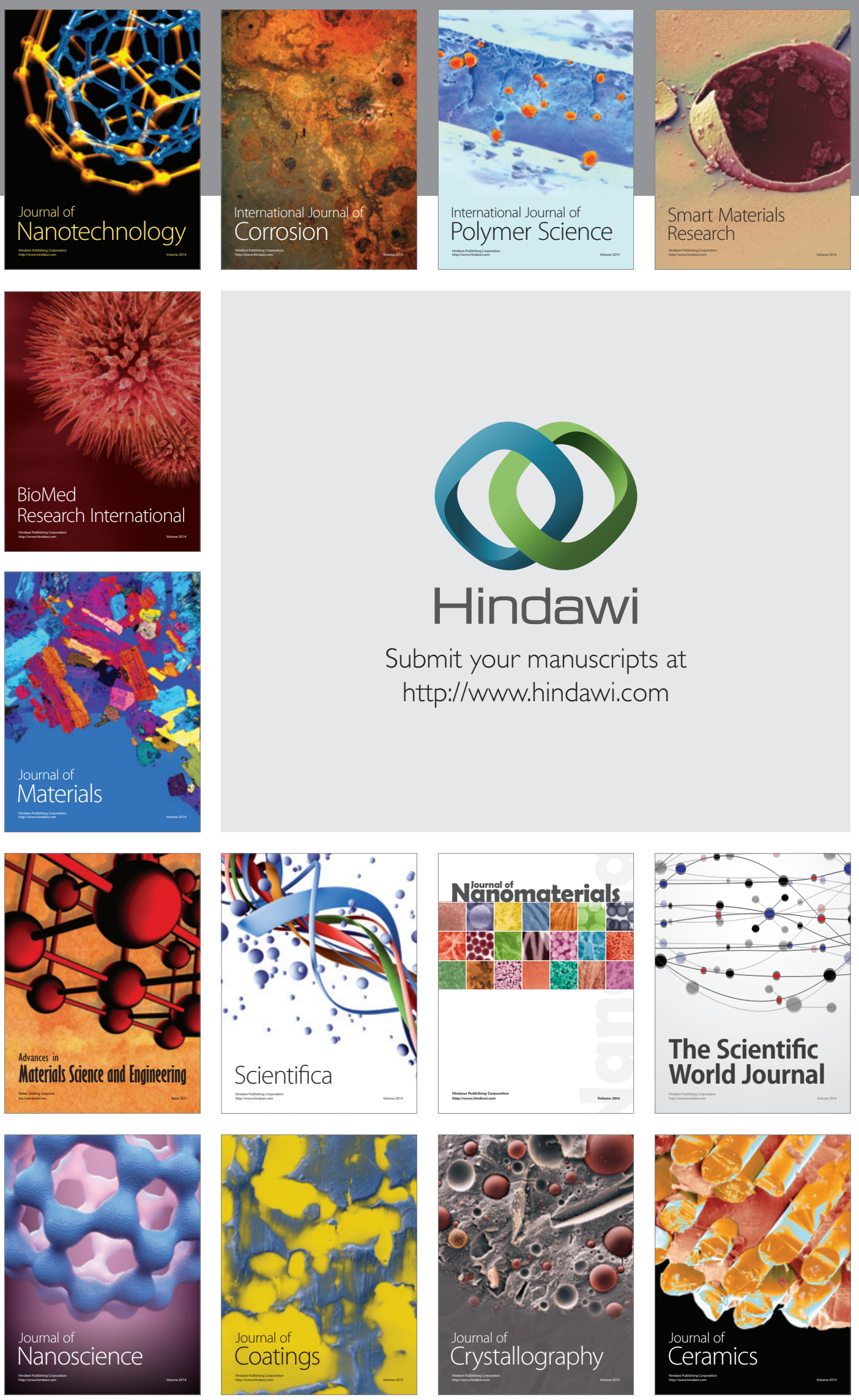

The Scientific World Journal

Submit your manuscripts at

http://www.hindawi.com

\section{World Journal}

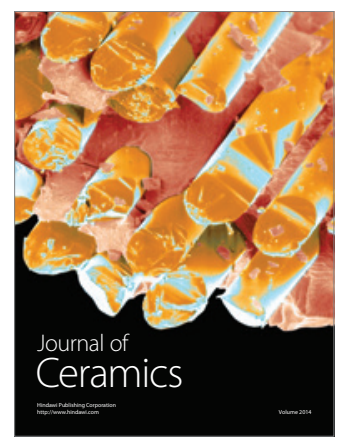

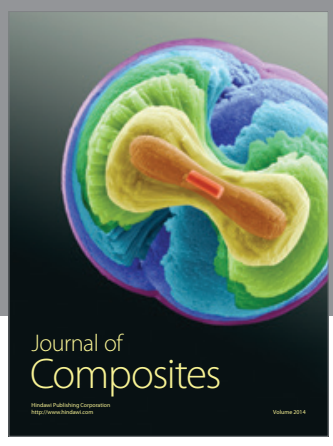
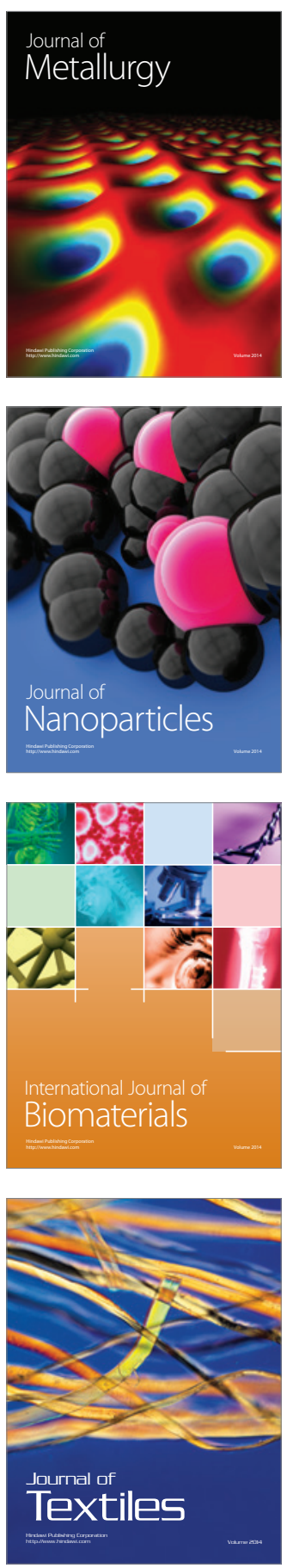